\title{
PERBANDINGAN WHOLE BODY REACTION TIME DAN ANTICIPATION REACTION TIME ANTARA ATLET KATA DAN KUMITE CABANG OLAHRAGA KARATE
}

\author{
Ramadhansyah Abdan Syaquro, Badruzaman \\ Program Studi Ilmu keolahragaan \\ Departemen Pendidikan Kesehatan dan Rekreasi \\ Fakultas Pendidikan Olahraga dan Kesehatan \\ Universitas Pendidikan Indonesia, Jl. Dr. Setiabudhi No. 299 Bandung \\ Email: kuro.ai8611@gmail.com
}

\begin{abstract}
Abstrak
Karate terbagi oleh dua kelas kata dan kumite. Whole body reaction time test dan anticipation reaction time adalah kebutuhan reaksi yang dimiliki seorang atlet karate. Tujuan penelitian ini ingin membuktikan whole body reaction dan anticipation reaction time atlet kumite lebih baik dari atlet kata tersebut benar adanya atau tidak, dikarenakan berpengaruh terhadap program latihan yang diberikan kepada atlet. Metode penelitian yang digunakan adalah deskriptif komparatif. Sample berjumlah 10 atlet kata dan 10 atlet kumite dengan teknik pengambilan sampling jenuh. Hasil dianalisis dengan spss ver.21 menunjukkan data whole body reaction time nilai $\mathrm{f}=4,508$ dan sig. 0,059 > 0,05 maka $\mathrm{H}_{0}$ diterima dan disimpulkan tidak ada perbedaan kecepatan whole body reaction time test dengan atlet kata dan kumite cabang olahraga karate, sedangkan data anticipation reaction time nilai $\mathrm{f}=1,787$ dan sig. $0,198>0,05$ maka $\mathrm{H}_{0}$ diterima dan disimpulkan tidak terdapat perbedaan kecepatan anticipation reaction time test dengan atlet kata dan kumite cabang olahraga karate.
\end{abstract}

Kata kunci: whole body reaction, anticipation reaction, kata, kumite.

\section{PENDAHULUAN}

Dalam karate baik kata maupun kumite memiliki esensi yang sama yaitu bertarung, dalam pertarungan atlet karate memerlukan reaksi yang cepat. Pentingnya reaksi bagi atlet karete menurut Ashley Croft (2009:30) menyatakan bahwa "The time a person taken to respond to a signal. A good reaction time is absolutely essential in karate, as it enables an opponent's body movements or attack to identified early, allowing decisive or evasive action to be taken if necessary." Dari kutipan tersebut dapat diartikan bahwa waktu reaksi seseorang diambil untuk menanggapi sinyal yang diberikan. Waktu reaksi yang baik sangat penting dalam karate, karena memungkinkan untuk mendidentifikasi lebih awal gerakan tubuh lawan atau serangan yang memungkinkan mengambil tindakan tegas atau mengelak akan diambil jika perlu. Hal tersebut dapat disimpulkan bahwa bagi seorang atlet karate membutuhkan reaksi yang cepat untuk melakukan pergerakan menyerang atau 
bertahan. Dalam Prestasi Karate berbagai macam komponen fisik sangatlah menunjang. Komponen Fisik terdapat reaksi, reaksi adalah komponen yang penting bagi atlet Karate dalam kompetisi kata dan kumite. Pelatih Karate di Indonesia selalu mengutamakan komponen reaksi hanya untuk kumite, sedangkan dalam kata kurang di perhatikan. Perbedaan perlakuan tersebut dikarenakan pemahaman karateka di Indonesia masih membedakan karate menurut spesialisasssi kelasnya saja. Perbedaan perlakuan dalam pemberian latihan komponen reaksi ini berimbas kepada performa atlet, begitu pula dalam reaksi atisipasi, reaksi ini sangatlah penting dalam olahraga beladiri seperti yang dikemukakan oleh Vayens, dkk (dalam Nuri Leila, 2013) menyatakan bahwa Anticipatory skill plays an important role in successful decision-making." , kutipan tersebut menjelaskan bahwa kemampuan antisipasi dalam permainan sangatlah berperan penting dalam pengambilan kepustusan. Hal ini dikarenakan semakin baiknya reaksi antisipasi maka semakin baik pengambilan keputusan ditengah pertandingan atau permainan. Menurut Nuri Laila (2013) "RT has been considered as a key strategy in competitive sports which require fast reactions such as karate”, pernyataan tersebut menjelaskan bahwa waktu reaksi adalah kunci dari olahraga yang kompetitif yang membutuhkan reaksi yang cepat seperti karate, tidak hanya dalam kelas kumite atau kelas kata. Pernyataan yang di kemukakan oleh Layton (dalam Nuri Laila 2013) menegaskan bahwa karate sangat membutuhkan waktu reaksi yang sangat baik untuk mendukung performa dilapangan.

\section{METODE}

Metode penelitian yang dilakukan dalam penelitian ini adalah metode penelitian komparatif , menurut Arikunto (dalam Sidik 2014) ialah yang menegaskan bahwa "penelitian kuantitatif yang sesuai dengan namanya banyak di tuntut menggunakan angka, mulai dari pengumpulan data, penafsiran terhadap data tersebut serta penampilan dari hasilnya." Jenis penelitian ini adalah jenis penelitian deskriptif komparatif. Menurut Sugiyono (2014) menyatakan bahwa "penelitian deskriptif digunakan untuk menganalisis data dengan cara mendeskripsikan atau menggambarkan data yang telah terkumpul sebagaimana adanya tanpa bermaksud membuat kesimpulan yang berlaku untuk umum atau generalisasi", dan menurut Sugiyono (2014) menyatakan bahwa "jenis penelitian komparatif adalah jenis penelitian yang membandingkan keberadaan satu variable atau lebih pada dua atau lebih sample yang berbeda, atau pada waktu yang berbeda." Penelitian ini mengetahui perbandingan hasil dari dua jenis test dengan alat whole body reaction time test dan anticipation reaction time test yang dilakukan oleh atlet kata dan kumite cabang olahraga beladiri karate untuk mengetahui waktu dari kecepatan reaksi masing - masing atlet untuk meningkatkan prestasinya.

Penelitian akan dilakukan di laboratorium FPOK Universitas Pendidikan Indonesia dengan melibatkan atlet karate UKM Karate UPI. Partisipan berada dikategori umur senior, dan memiliki pengalaman pertandingan kata dan kumite tingkat provinsi dan nasional. 


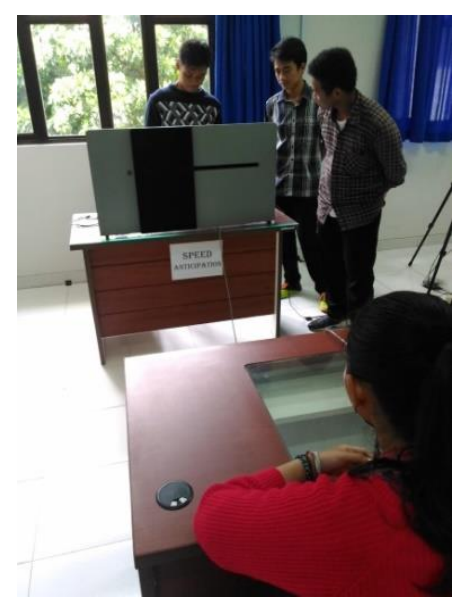

Gambar 1. Sample sedang melakukan anticipation reaction test. (sumber : peneliti)

Teknik pengambilan sample menggunakan teknik sampling jenuh. maka sample yang akan diambil sebanyak 10 atlet karate kumite dan 10 atlet karate kata dari 20 atlet UKM KARATE UPI.

Untuk mengetahui hasil whole body reaction time dan coordination reaction time dari atlet kata dan kumite cabang olahraga beladiri karate, menggunakan yang berada di laboratorium FPOK Universitas Pendidikan Indonesia, diantaranya :

\section{Anticipation Reaction Time Test}

Tujuan

Mengukur kecepatan reaksi antisipasi setelah stimulus diberikan.

a. Nama Alat: Speed Anticipation Time

b. Pelaksanaan

Subyek duduk didepan alat. Tempatkan dagu diatas penahan dagu senyaman mungkin. Subyek akan memerhatikan cahaya yang akan melintas di hadapan mata subyek. Setelah cahaya tersebut menghilang, subyek memperkirakan waktu cahaya tersebut untuk kembali muncul dengan menekan tombol merah. Lakukan sebanyak 3 kali c. Skor : Catat waktu terbaik dari 3 kali percobaan.

2. Whole Body Reaction Time

a. Tujuan : Mengukur kecepatan reaksi gerak keseluruhan tubuh dari stimulus visual

b. Nama Alat: Whole Body Reaction Type II

c. Pelaksanaan

Subyek berdiri di atas matras yang terbuat dari karet dan didalamnya terdapat sensor dengan posisi kaki menekuk sedikit lututnya agar tidak menjadi hambatan ketika bereaksi setelah stimulus diberikan. Ketika tester menekan tombol, maka akan keluar stimulus berupa cahaya dan subyek melompat dari pijakan karet yang terdapat sensor.Lakukan sebanyak 3 kali.

Skor : Catat waktu terbaik dari 3 kali kesempatan.

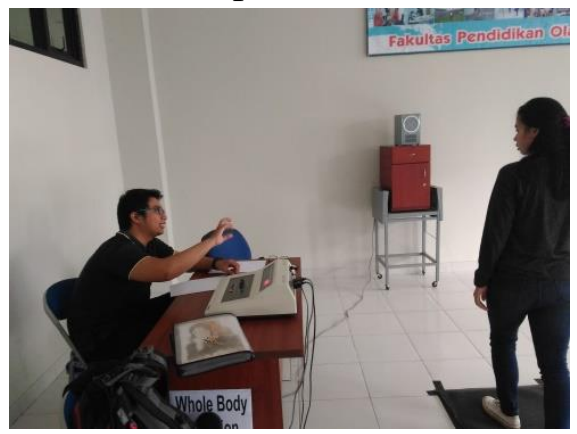

Gambar 2. Sample sedang melakukan whole body reaction time test (sumber : peneliti)

Data yang dianalisis pada penelitian ini Menggunakan statistika Induktif uji-T yaitu Independent Sample T-Test untuk mengetahui nilai whole body reaction time test dan anticipation reaction time test antara atlet Kata dan Kumite yang terlebih dahulu menggunakan uji normalitas menggunakan Kolmogorov-Smirnoff dan uji homogenitas menggunakan Levene Test. 
Pengolahan dan analisis data merupakan rangkaian yang dilakukan sebagai upaya untuk memperoleh kesimpulan penelitian. Analisis data dilaksanakan dengan menggunakan program Statistical Product for Social Science (SPSS) Seri 17.

\section{HASIL DAN PEMBAHASAN}

Pada kelompok atlet kata hasil rata rata dari whole body reaction time test adalah 0.239 detik, dengan hasil tercepat adalah 0.074 detik dan hasil terlambatnya adalah 0.353 detik, sedangkan hasil rata rata adalah 0.239 detik. Pada kelompok atlet kumite dalam whole body reaction time test memiliki hasil rata - rata 0,320 detik, dengan nilai tercepat dengan hasil 0.277 detik dan terlambat adlah 0,401 detik Kelompok sample atlet kata memiliki kecepatan rata - rata yang sedikit cepat dibandingkan atlet kumite.

Tabel 1. Deskripsi data Whole Body Reaction Time Test

\begin{tabular}{|l|l|l|l|l|c|}
\hline Kls & N & Min & Max & Mean & $\begin{array}{c}\text { Std. } \\
\text { Deviation }\end{array}$ \\
\hline Kata & 10 & 0.074 & 0.353 & 0.239 & 0.88360 \\
\hline Kumite & 10 & 0.277 & 0.401 & 0,320 & 0.04055 \\
\hline
\end{tabular}

Anticipation reaction time test kedua kelompok sample memiliki kecepatan yang sama yaitu tercepat adalah 0.01 detik dan yang terlambat adalah 0.06 detik, namun yang berbeda adalah jumlah rata - rata yang berbeda. Kelompok sample Kata memiliki waktu rata - rata kecepatan antisipasi sebesar 0.030 detik, sedangkan kumite memiliki waktu rata - rata sebesar 0.024 detik.
Tabel 2. Deskripsi data Anticipation

\section{Reaction Time Test}

\begin{tabular}{|l|l|l|l|l|l|}
\hline Kelas & $\mathrm{N}$ & Minimu & Maximu & Mea & Std. \\
$\mathrm{m}$ & $\mathrm{m}$ & & $\begin{array}{l}\text { Deviati } \\
\text { on }\end{array}$ \\
\hline Kata & 1 & 0.01 & 0.06 & 0.03 & 0.2055 \\
& 0 & & & 0 & \\
\hline Kumit & 1 & 0.01 & 0.06 & 0.02 & 0.1647 \\
e & 0 & & & 4 & \\
\hline
\end{tabular}

Setelah melalui proses analisis data yang diolah oleh SPSS v.21 dengan metode independent simple t-test bahwa perbandingan hasil whole body reaction time test dan anticipation reaction time test antara atlet kata dan kumite cabang olahraga karate tidak memiliki perbedaan yang signifikan.

Tabel 3

Uji Normalitas Data

\begin{tabular}{|l|l|l|l|l|}
\hline Variabel & $\begin{array}{l}\text { K.Smirno } \\
v Z\end{array}$ & Sig. & Kep & Sim \\
\hline $\begin{array}{l}\text { Whole } \\
\text { Body RT }\end{array}$ & 0.849 & 0.46 & $\begin{array}{l}\mathrm{H}_{0} \\
\text { Diterim }\end{array}$ & $\begin{array}{l}\text { Data } \\
\text { Norma } \\
1\end{array}$ \\
\hline $\begin{array}{l}\text { Anticipatio } \\
n \text { RT }\end{array}$ & 0.995 & 0.27 & $\begin{array}{l}\mathrm{H}_{0} \\
\text { Diterim }\end{array}$ & $\begin{array}{l}\text { Norma } \\
1\end{array}$ \\
\hline
\end{tabular}

Hasil bahwa tidak terdapat perbedaan kecepatan yang signifikan antara hasil whole body reaction time test dan anticipation reaction time test dengan atlet kata dan kumite. Kecepatan reaksi atlet karate dalam penelitian yang dilakukan oleh Shuji Mori, Yoshio Ohtani, Kuniyasu Imanaka yang berjudul REACTION 
TIMES AND ANTICIPATORY SKILLS OF KARATE ATHLETES diperoleh hasil kecepatan reaksi dan reaksi antisipasi atlet kumite rata - rata memiliki kecepatan 230ms. Dalam penelitian tersebut atlet karate memiliki dua tahap pengolahan informasi ketika mengantisipasi serangan musuh, ketiga tahap itu adalah menyerap informasi pada gerakan pertama dan menaksirkan informasi tersebut kepada target area. Contohnya jika lawan menyerang dengan pukulan jodan tsuki kearah kepala, pertama karateka akan menyerap informasi dari gerakan pertama lawan yang akan mengeluarkan pukulan dan kemudian akan ditaksirkan kemana target pukulan itu akan dilayangkan, setelah itu karateka akan mengantisipasi dengan gerakan age-uke atau tangkisan atas. Dalam penelitian tersebut diketahui bahwa kemampuan antisipasi atlet karate adalah bersifat preseptual. Seorang atlet karate memiliki antisipasi yang sangat baik dalam mengekstraksi informasi yang didapat lebih cepat dari pada murid karate biasa, reaksi dan reaksi antisipasi preseptual sangat penting dikarenakan menguntungkan atlet untuk meningkatkan performa bertanding.

Dalam penelitian Coskun Betul,dkk dalam penelitian THE COMPARISON OF REACTION TIMES OF KARATE ATHLETES ACCORDING TO AGE, GENDER AND STATUS diperoleh data bahwa kebutuhan atlet karate untuk level internasional adalah 0,035 detik untuk simple reaction test, 0,064 detik untuk choice reaction time test dan 0,033 detik untuk auditory reaction time test, dalam penelitian tersebut dijelaskan bahwa umur, jenis kelamin, dan level dalam kompetisi sangat memengaruhi hasil test dan yang paling memengaruhi kecepatan reaksi adalah umur.
Menurut Mori, Ohtani \& Imanaka (2002) dalam Coskun Betul, dkk (2014) menjelaskan bahwa Karate adalah jenis olahraga tingkat tinggi kompetitif memerlukan reaksi cepat. Kemampuan untuk memahami informasi dengan cepat dan benar menyederhanakan pengambilan keputusan dan memberikan lebih banyak waktu untuk pelaksanaan gerak motorik yang merupakan kebutuhan seorang atlet karate guna meningkatkan performa dalam pertandingan baik itu dalam kumite dan kata.

Dalam aplikasinya kemampuan reaksi kata dilakukan menjadi aksi ketika mendapatkan rangsangan dari pola antisipasi preseptual dalam suatu kata. Atlet kata akan kesulitan menampilkan sebuah performa yang baik jika tidak memiliki reaksi yang baik, dan jika atlet kata tidak memiliki reaksi antisipasi yang baik maka atlet kata akan kehilangan esensi gerak dan irama yang dibutuhkan karena berhubungan dengan rekasi yang dihasilkan rangsangan dari pengambilan keputusan antisipasi yang berarti kata adalah bertarung melawan lawan imajiner. Dalam aplikasi kumite, reaksi diperlukan ketika atlet mendapatkan kesempatan untuk mencuri poin dari lawan, dan antisipasi diperlukan ketika lawan menyerang.

Hal ini menunjukkan bahwa kecepatan reaksi seorang atlet karate memiliki kecepatan reaksi yang sama cepat walau telah memiliki spesifikasi kelas, yaitu kata dan kumite. Kembali kepada konsep dasar karate yang merupakan cabang olahraga seni beladiri yang memfokuskan terhadap sebuah pertarungan tangan kosong. Dalam karate terdapat dua kelas spesifikasi dalam sebuah pertandingan, yaitu kata dan kumite. Dalam buku yang di tulis oleh Ashley Croft yang berjudul 
INTERMEDIATE SHOTOKAN KARATE UNRAVELLING THE BROWN BELT AND FIRST BLACK BELT KATA diperoleh sebuah pernyataan bahwa berlatih karate memiliki banyak keuntungan, salah satunya adalah meningkatnya reaksi atlet karate, hal ini dikarenakan waktu reaksi yang baik sangat penting dalam karate, karena memungkinkan untuk mendidentifikasi lebih awal gerakan tubuh lawan atau serangan yang memungkinkan mengambil tindakan tegas atau mengelak akan diambil jika perlu, dalam karate selalu melatih kecepatan reaksi dan reaksi antisipasi tanpa di sadari, ketika selalu berlatih kata. Oleh karena itu atlet kata memiliki kecepatan reaksi dan antisipasi yang tidak kalah cepat dengan kumite. Hal ini ditegaskan oleh Shoshin Nagamine dalam buku THE ESSENCE OF OKINAWAN KARATE-DO bahwa kata adalah serangkaian gerakan yang terorganisir secara sistematis dari teknik bertahan dan menyerang dilakukan dalam berurutan terhadap satu atau lebih lawan imajiner, dan diberi pola linear simetris. Hal ini dapat ditarik kesimpulan bahwa kata memiliki kapasitas reaksi yang sama dengan kumite dikarenakan kata merupakan sebuah pertarungan yang dirangkai dan di tentukan dengan sebuah jurus melawan lawan imajiner, jadi kata dan kumite memiliki kemampuan yang sama. Karate sesungguhnya tidak membagi - bagi spesialisasi seorang karateka, namun kebutuhan dalam kompetisi membagi karate menjadi dua kecabangan yaitu kata dan kumite. Karate mempunyai sistematis latihannya tersendiri, yang pertama karateka harus melatih teknik dasar secara terus menerus dengan intensitas yang meningkat sesuai dengan tingkatan sabuk kemudian mempelajari kata lalu yang terakhir kumite. Kata adalah kumpulan teknik dasar, dan kumite adalah aplikasi teknik dasar dalam bertarung, semua bersinergi menjadi satu tidak ada perlakauan yang berbeda dalam pemberian latihan. Kebutuhan dalam kompetisi ini menjadikan beberapa presepsi yang kurang tepat, dalam kompetisi karate baik kelas kata dan kumite yang dimulai dari usia dini hingga senior membuat anak - anak usia dini di berikan spesialisasi kelas dalam pertandingan karate.

\section{KESIMPULAN}

Tidak terdapat perbedaan kemampuan whole body reaction time yang signifikan antara atlet kata dan kumite. Berdasarkan hasil temuan pengolahan dan analisis data peneliti dapat memberikan kesimpulan sample yang berjumlah 20 orang yang terbagi dua kelompok yaitu kelompok atlet kata dan kelompok atlet kumite. Pada kelompok atlet kata, hasil rata - rata dari whole body reaction time test adalah 0.239 detik, dengan hasil tercepat adalah 0.074 detik dan yang paling lambat adalah 0.353 detik, sedangkan hasil rata - rata adalah 0.239 detik. Pada kelompok atlet kumite dalam whole body reaction time test memiliki hasil rata - rata 0,320 detik, dengan nilai tercepat dengan hasil 0.277 detik dan yang paling lambat adalah 0,401 detik.

Tidak terdapat perbedaan kemampuan anticipation reaction time yang signifikan antara atlet kata dan kumite. Kelompok sample atlet kata memiliki kecepatan rata rata yang sedikit cepat dibandingkan atlet kumite. Sedangkan dalam anticipation reaction time test kedua kelompok sample memiliki kecepatan yang sama yaitu tercepat adalah 0.01 detik dan yang 
terlambat adalah 0.06 detik, namun yang berbeda adalah jumlah rata - rata yang. Kelompok sample Kata memiliki waktu rata - rata kecepatan antisipasi sebesar 0.030 detik, sedangkan kumite memiliki waktu rata - rata sebesar 0.024 detik.

Kemampuan whole body reaction time test dan anticipation reaction time test atlet kumite tidak lebih baik daripada atlet kata, data tersebut didapatkan setelah diolah dan mendapatkan hasil bahwa tidak ada perbedaan yang signifikan antara whole body reaction time test dan anticipation reaction time test dengan atlet kata dan kumite

\section{DAFTAR PUSTAKA}

Ajay M. Gavkare, dkk (2013) . Auditory Reaction Time, Visual Reaction Time and Whole Body Reaction Time in Athletes. Indian Medical Gazette. Hlm. 214 - 218

Croft Ashley. (2009). Intermediate Shotokan karate Unravelling the Brown Belt and First Black Belt Kata. Ramsbury: The Crowood Perss Ltd.

Coskun , B . dkk (2014). The Comparison of reaction times of karate athlete aaccording to age, gender, and status. Journal Science, Movement, and Healt, 14(2).hlm. 97 - 101

Dawes Jay, dkk (2012) . Developing Agility And Quickness. Amerika Serikat ; National Strength and Conditioning Association.

Giriwijoyo. H.Y.S Santosa (2010) Fisiologi Olahraga. Bandung: FPOK UPI

Imanudin,Iman. (2014). Modul Mata Kuliah Ilmu Kepelatihan Olahraga. Bandung: FPOK UPI.

Koropanovski , N. dkk (2011). Anthopometric and physical performance profile of elite karate kumite and kata competitors. Journal of Human Kinetics, 30/2011, hlm. 107 -114.

Erickson,Kevin. (2015). Perbandingan Kecepatan Reaksi dan Antisipasi Reaksi pada Penjaga Gawang Olahraga Sepakbola dan Futsal. Bandung: UPI.

Emzir. (2012). Metodologi Penelitian Pendidikan; Kuantitatif dan Kualitatif. Jakarta; PT Rajagrafindi Persada

Leila Nuri . dkk (2013) Reaction time and anticipatory skill of athletes in open and closed skilldominated sport. European Journal of Sport Science. 13(5). Hlm. 431 - 436.

Mori, S., Ohtani, Y., \& Jmanaka, K. (2002). Reaction times and anticipatory skills of karate athletes. Human Movement Science. 21(2). Hlm. 213 - 230.

Nagamine Shoshin. (1976). The Essence of Okinawan Karate, (edisi keenambelas). Tokyo: The Charlie E. Tuttlt Company, Inc.

Nakayama Masatoshi. (1978). Best Karate kumite Vol.1. Tokyo: Kodansha International Ltd.

Permatasari, N.K.T. (2015). Pengembangan Alat Ukur Waktu Reaksi Tangan Berbasis MicroController. Bandung : UPI

Sugiyono. (2012). Statistika untuk Penelitian. Bandung: Alfabeta.

Yazid, Sidik. (2015). Hubungan Konsentrasi Dengan Hasil Pukulan Jarak Jauh (Long Stroking) pada Cabang Olahraga WoodBall. Bandung: UPI

Sugiyono (2014) : Metode Penelitian Kuantitatif Kualitatif dan R\&D. Bandung : Alfabeta 